|| ISSN(online): 2589-8698 || ISSN(print): 2589-868X ||

International Journal of Medical and Biomedical Studies

Available Online at www.ijmbs.info

NLM (National Library of Medicine ID: 101738825)

Index Copernicus Value 2019: 79.34

Original Research Article

Volume 5, Issue 1; January: 2021; Page No. 175-178

\title{
CYTO-HISTOPATHOLOGICAL CORRELATION OF THYROID LESIONS
}

\section{Dr. Dharmendra Singh Bhadouria ${ }^{1}$ (PG Resident), Dr. Shikha Raghuwanshi ${ }^{2}$ (PG Resident) \& Dr. Arun Saxena ${ }^{3}$ (Professor)}

Department of Pathology, Index Medical College Hospital and Research Centre, Indore ${ }^{1,2 \& 3}$

Article Info: Received 14 December 2020; Accepted 18 January 2021

DOI: https://doi.org/10.32553/ijmbs.v5i1.1664

Corresponding author: Dr. Dharmendra Singh Bhadouria

Conflict of interest: No conflict of interest.

\begin{abstract}
Introduction: Thyroid nodules show an overall incidence rate of 4-7\% \& high probability of malignancy, constituting 5\% to $35 \%$. FNAC of Thyroid is most economical and reliable preoperative procedure to distinguish between neoplastic and nonneoplastic lesion.

Objectives: To Study Cyto-Morphology of Fine Needle Aspiration of Thyroid nodules. To find out incidence of various types of lesions as per age \& sex and to confirm the findings with Histomorphological diagnosis of same nodule.

Material \& Methods: 100 patients with Thyroid nodule who underwent FNAC \& Thyroidectomy taken for an observational study from January 2019 to June 2020. The cytological findings were correlated with histopathological diagnosis.

Results: Out of 100 cases 14 cases were found to be malignant and 86 were found to be benign on histology while cytology showed 93 cases benign and 7 malignant cases .Out of 5 cases suspicious for neoplasm and 3 cases were of follicular neoplasm on cytology which confirmed as papillary carcinoma on histopathology.2 cases which were diagnosed as Benign Thyroid lesion turned out to be papillary carcinoma and 2 cases which were diagnosed as colloid goitre on cytology turned out to be papillary carcinoma on histo pathology .1 case diagnosed as follicular hyperplasia turned out to be papillary carcinoma on histology.1 case diagnosed as MNG in cytology was turned out to be papillary carcinoma on histo pathology.

Conclusion: Thyroid cytology proves to be a reliable, simple and cost-effective first line diagnostic procedure with high patient acceptance and without complications. FNAC serves as useful screening test for thyroid lesions. However, inability in distinguishing follicular lesion and inadequate sampling in cystic lesion lead to false diagnosis.
\end{abstract}

Keywords: Histopathology, Thyroid , Lesion.

\section{Introduction}

Thyroid gland is afflicted by various pathologies ranging from diffuse enlargement (goiter) to nodular lesions, thyroiditis, and malignancies. The incidence of thyroid diseases is increasing in recent years due to goitrogens and changing food habits.(1)

The prevalence of thyroid swelling ranges from $4 \%$ to $10 \%$ in the general adult population and from $0.2 \%$ to $1.2 \%$ in children.(2)In surgical practice, thyroid lesions are common, observed in 4-7\% of the population and affect women more commonly than men. Excising all the thyroid lesions is impracticable and associated with risk.(3)

A solitary thyroid lesion is defined as a palpable single, clinically detected nodule in the thyroid. They cause more concern because of high probability of malignancy in them, which can range from $5-35 \%$ of all solitary thyroid nodules.(4)

Diffuse thyroid lesions are those that are associated with conditions affecting entire gland such as hyperplasia and thyroiditis. Nodular lesion comprises those disorders that produce a clinical nodule and consists of non-neoplastic hyperplasia as well as benign and malignant tumours.(5)
Accurate diagnosis of thyroid lesion is necessary for appropriate clinical management of these patients and to avoid unnecessary surgical interventions. The majority of clinically diagnosed thyroid nodules were benign in nature and those requiring surgical intervention due to malignant lesions were 5-20\%.(6)

Inspite of great advances in the understanding of thyroid lesions, there are problems and unanswered questions. The great variety of types and the wide range of aggressiveness of thyroid cancers continue to complicate both diagnosis and management. Evaluation of different methods of therapy continues to be a problem, partly because thyroid cancers are uncommon.

\section{Material \& Method}

A Prospective, Cross-sectional, Observational Study at Index Medical College Hospital and Research Centre, Indore, Madhya Pradesh from January 2019 to June 2020, Patients with thyroid nodule/es with Sample Size of 100 patients.

\section{Inclusion Criteria:}

- All Patients with thyroid swelling, irrespective of age and gender, 
- All those who underwent any type of thyroid operation

\section{Exclusion Criteria:}

1. Patient not willing to give written informed consent.

2. Patients with inadequate and sub optimal smear

3. Patients not willing for USG-guided / unguided fine needle aspiration cytology of their thyroid lesions even after explaining the purpose, utility and consequence of the procedure were excluded from the study.

\section{Data Collection and Methods}

1. Hundred clinically diagnosed thyroid lesion cases who have undergone Ultrasonography \&cytological examination (FNAC) were studied.

2. In each patient detailed clinical history was obtained and thorough clinical examination was done prior to procuring sample for cytological study using proforma.

3. In cytology study, aspirated material was alcohol fixed and stained with pap stain and air dried smear was stained with Modified Giemsa Grunwald (MGG) stain.

4. In case where excisional surgery was carried out, the specimen was received and immediately fixed in $10 \%$ buffered formalin.

5. The sample was processed in an automatic tissue processor for paraffin block preparation and section was routinely stained with Hematoxylin \& Eosin.

6. Histopathological study was carried out and correlated with Cytological \& Radiological findings.

\section{Ultrasonography (USG) examination of thyroid lesions:}

The gland morphology is studied by ultrasonography. USG was thus performed in all cases to distinguish cystic and solid lesions and by echogenic pattern, to distinguish benign from malignant thyroid lesions. The echogenicity of thyroid nodule refers to its brightness compared to the normal thyroid parenchyma. A nodule was characterized as hypoechoic, isoechoic, hyperechoic or anechoic. Hypoechogenicity was associated with thyroid malignancy.

Impalpable thyroid lesions of size, less than $1 \mathrm{~cm}$ in diameter were commonly detected during USG examination of head and neck. Very small incidental thyroid lesions less than $1 \mathrm{~cm}$ diameter, were not sampled, unless there were other indications like suspicious USG appearance, a family history or prior radiation to the head and neck region.

\section{Statistical Analysis}

All the data analysis was performed using IBM SPSS ver. 20 software. Frequency distribution and cross tabulation was used to prepare the tables. Quantitative data was expressed as mean and standard deviation whereas categorical data was expressed as number and percentage. Mean was compared using independent sample t test and paired $\mathrm{t}$ test .Categorical data was compared using Chi Square test. $\mathrm{P}$ value of $<0.05$ was considered as significant.

\section{Results}

Table 1: Age distribution of patients with thyroid lesions

\begin{tabular}{lll}
\hline Age group (years) & No of patients & Percentage \\
\hline$<20$ & 2 & 2.0 \\
\hline $21-30$ & 30 & 30.0 \\
\hline $31-40$ & 26 & 26.0 \\
\hline $41-50$ & 21 & 21.0 \\
\hline $51-60$ & 18 & 18.0 \\
\hline$>60$ & 3 & 3.0 \\
\hline Total & 100 & 100.0 \\
\hline Mean \pm SD & $39.34 \pm 12.89$ Years \\
\hline Range & $12-70$ Years \\
\hline
\end{tabular}

In present study table 1 shows the age distribution of patients with thyroid lesions.

The mean age of the patients with thyroid lesion was 39.34 \pm 12.89 years which ranged from $12-70$ years.

As per the table 1 majority of the patients with thyroid lesions had age between 21-30 years (30\%), followed by $31-40$ years $(26 \%)$ and $41-50$ years $(21 \%)$. There were $21 \%$ patients with thyroid lesion had age between 41-50 years and 18\% had age between 51-60 years. This highlighted that thyroid lesions were more common in young working age group $(58 \%)$ or in other words prevalence of thyroid lesions was highest in young working age group.

Table 2: Showing clinical symptoms in patients with thyroid lesions

\begin{tabular}{lll}
\hline Clinical symptoms & Frequency & Percent \\
\hline Neck swelling & 100 & 100.0 \\
\hline
\end{tabular}

Table 2 shows the distribution of patients with thyroid lesions according to clinical symptoms.

As per the table 4 all the patients with thyroid lesion had neck swelling (100\%) which meant neck swelling is the main characteristic of the patients with thyroid lesions.

Table 3: Showing Histological diagnosis of 100 patients

\begin{tabular}{lll}
\hline Histological diagnosis & Frequency & Percent \\
\hline Colloid Goiter & 14 & 14.0 \\
\hline Granulomatous Thyroiditis & 1 & 1.0 \\
\hline Hashimotto Thyroiditis & 11 & 11.0 \\
\hline Hemorhagic cyst & 1 & 1.0 \\
\hline Lymphocytic Thyroiditis & 4 & 4.0 \\
\hline MNG & 55 & 55.0 \\
\hline Papillary Carcinoma & 14 & 14.0 \\
\hline Total & 100 & 100.0 \\
\hline
\end{tabular}

Table 3 shows the Histological diagnosis of 100 patients with thyroid lesions. It was revealed that majority of the thyroid lesion patients had Multinodular goiter (MNG) $(55 \%)$ followed by Colloid Goiter (14\%), Papillary 
Carcinoma (14\%) and Hashimotto Thyroiditis (11\%). Lymphocytic Thyroiditis was observed in 4\%, Granulomatous Thyroiditis in 1\% and Hemorhagic cyst $1 \%$ patients with thyroid lesions.

Table 4: Comparison of cytological diagnosis, pattern diagnosis of 100 patients with histological diagnosis

\begin{tabular}{lllllllll}
\hline $\begin{array}{l}\text { Cytological } \\
\text { diagnosis }\end{array}$ & \multicolumn{9}{l}{ Histological Diagnosis } & & & \multirow{2}{*}{ Total } \\
\cline { 2 - 7 } & CG & GT & HT & HC & LT & MNG & PC & \\
\hline $\begin{array}{l}\text { Autoimmune } \\
\text { Thyroiditis }\end{array}$ & 0 & 0 & 0 & 0 & 0 & 1 & 0 & 1 \\
\hline $\begin{array}{l}\text { Benign } \\
\text { Follicular Lesion }\end{array}$ & 0 & 0 & 0 & 1 & 0 & 1 & 0 & 2 \\
\hline BTL & 7 & 1 & 1 & 0 & 1 & 31 & 2 & 43 \\
\hline Colloid Goiter & 5 & 0 & 4 & 0 & 0 & 10 & 2 & 21 \\
\hline $\begin{array}{l}\text { Folicular } \\
\text { Neoplasm }\end{array}$ & 0 & 0 & 0 & 0 & 1 & 1 & 3 & 5 \\
\hline $\begin{array}{l}\text { Follicular } \\
\text { Hyperplasia }\end{array}$ & 0 & 0 & 1 & 0 & 0 & 0 & 1 & 2 \\
\hline $\begin{array}{l}\text { Granulomatous } \\
\text { Thyroiditis }\end{array}$ & 0 & 0 & 0 & 0 & 0 & 1 & 0 & 1 \\
\hline $\begin{array}{l}\text { Hashimotto } \\
\text { Thyroiditis }\end{array}$ & 0 & 0 & 1 & 0 & 0 & 1 & 0 & 2 \\
\hline MNG & 0 & 0 & 1 & 0 & 0 & 9 & 1 & 11 \\
\hline SFN & 0 & 0 & 0 & 0 & 0 & 0 & 5 & 5 \\
\hline Thyroiditis & 2 & 0 & 3 & 0 & 2 & 0 & 0 & 7 \\
\hline Total & 14 & 1 & 11 & 1 & 4 & 55 & 14 & 100 \\
\hline $\begin{array}{l}\text { Pearson Chi } \\
\text { Square Value }\end{array}$ & 144.977 & & & & & & \\
\hline P value & $<0.001$ & & & & & & \\
\hline
\end{tabular}

CG; ColloidGoiter, GT; Granulomatous Thyroiditis, HT; Hashimotto Thyroiditis, HC; Hemorhagic cyst, LT; Lymphocytic Thyroiditis, PC; Papillary Carcinoma, SFN; Suspicious for Neoplasm, BTL; Benign Thyroid Lesion, MNG; Multi Nodular Goitre

Table 04 is showing comparison of cytological diagnosis of 100 patients with histological diagnosis. It was revealed that most common thyroid lesion in cytological diagnosis was benign thyroid lesion $(n=43)$ however, out of these 43 patients who had benign thyroid lesion in cytology, 31 were confirmed to have Multi Nodular Goitre, 7 were confirmed to have Colloid Goiter, 2 had papillary carcinoma and one each also had Lymphocytic Thyroiditis, Hashimotto Thyroiditis and Granulomatous Thyroiditis in histology report.

Out of 21 who were found to have Colloid Goiter in cytology, only 5 patients were confirmed to have Colloid Goiter in histology, however, 10 patients had Multi Nodular Goitre in histological findings, 4 patients had confirmation for Hashimotto Thyroiditis and 2 were confirmed to have papillary carcinoma after histological diagnosis.

Out of 11 patients who had Multi Nodular Goitre in cytology, 9 were confirmed in to have Multi Nodular Goitre in histology, whereas one patients each who were diagnosed to have Colloid Goiter in cytology had papillary carcinoma and Thyroiditis in histological diagnosis.

Out of 7 patients who were found to have Thyroiditis in cytology, upon histology confirmation were found to have Hashimotto Thyroiditis $(\mathrm{n}=3)$, Lymphocytic Thyroiditis $(\mathrm{n}=2)$ and Colloid Goiter $(\mathrm{n}=2)$.

Out of 5 patients with Suspicious for Neoplasm, all were confirmed to have Papillary carcinoma in histology examination.

Out of 5 patients with Folicular Neoplasm in cytology, 3 were found to have Papillary carcinoma and one each was found to have Multi Nodular Goitre and Lymphocytic Thyroiditis in histology examination.

Out of 2 patients with Follicular Hyperplasia in cytology, histological confirmation revealed to have Hashimotto Thyroiditis and Papillary Carcinoma in one patient each. Hoever out of 2 patients to have Hashimotto Thyroiditis in cytology, one showed confirmation for Hashimotto Thyroiditis whereas another showed confirmation for Multi Nodular Goitre.

Similarly of the 2 patients' who were found to have Benign Follicular Lesion in cytology, turned to have Multi Nodular Goitre and Hemorhagic cyst in one each after histology.

In cytology one patients each was diagnosed to have Autoimmune Thyroiditis and Granulomatous Thyroiditis which upon histological assessment turned to have Multi Nodular Goitre in both.

\section{Discussion}

The Histological diagnosis of 100 patients with thyroid lesions. It was revealed that majority of the thyroid lesion patients had Multinodular goiter (MNG) $(55 \%)$ followed by Colloid Goiter (14\%), Papillary Carcinoma (14\%) and Hashimotto Thyroiditis (11\%). Lymphocytic Thyroiditis was observed in $4 \%$, Granulomatous Thyroiditis in $1 \%$ and Hemorhagic cyst in $1 \%$ patients. Finding of Hathila et al are in line with the present study findings where in histologically it was found that benign lesions were follicular adenoma and malignant lesions were papillary carcinoma(7) It was revealed in Cytological diagnosis of 100 patients that majority had benign thyroid lesion (BTL) (43\%) followed by Colloid Goiter (21\%), Multinodular goiter (MNG) (11\%) and Thyroiditis (7\%). There were some less common cytological findings like 5\% were found to be suspicious for follicular neoplasm (SFN), Folicular Neoplasm in 5\%, Benign Follicular Lesion in 2\%, Hashimotto Thyroiditis in 2\%, Follicular Hyperplasia in $2 \%$, Autoimmune Thyroiditis in $1 \%$ and Granulomatous Thyroiditis in $1 \%$ patients .

\section{Conclusion}

Thyroid cytology proves to be a reliable, simple and costeffective first line diagnostic procedure with high patient 
acceptance and without complications. FNAC serves as useful screening test for thyroid lesions. However, inability in distinguishing follicular lesion and inadequate sampling in cystic lesion lead to false diagnosis. The procedure has higher sensitivity and specificity than the radiological assessment of patients and hence can be followed as a preoperative diagnostic modality in the management of patients with thyroid lesions, thus reducing the number of surgeries.

\section{References}

1. Prabha V, Bhuvaneswari MG. A Study of Histopathological Spectrum of Thyroid Lesions: An Observational Study. Int J Sci Stud 2019;7(1):1-4.

2. Kopperundevi V. Histopathological review of thyroid swellings a retrospective study. International Journal of Medical and Health Research. 2016; 2; (5):10-3.

3. Ramteke DJ, Mulay PS. Cyto-histopathological correlation of thyroid lesions. Int $\mathrm{J}$ Res Med Sci 2017;5:1425-9.

4. Ananthakrishnan N, Rao KM, Narasimhans R, Veliath, Smilet SR, Jagadish S. The Single Thyroid Nodule: A South Indian Profile of 503 Patients with Special Reference to Incidence of Malignancy. Indian J Surg 1993;55(10):487-92.

5. Baloch ZW, LiVolsi VA, Asa SL. Diagnostic terminology and morphologic criteria for cytologic diagnosis of thyroid lesions: a synopsis of the National Cancer Institute Thyroid Fine- Needle Aspiration State of the Science Conference. DiagnCytopathol2008; 36(6):425-37.

6. Gupta KP, Gupta A, Gupta A. Radiopathological Correlation of Thyroid Masses: A Prospective Study. Int J Sci Stud 2019;7(3):89-93.

7. Hathila N, Agrawal D. Comparison of radiological and histocytological examination of thyroid lesions in Udaipur area. Int $\mathbf{J}$ Med Sci Public Health 2016;5:2592-6.

8. Sharma R, Verma N, Kaushal V, Sharma DR, Sharma D. Diagnostic accuracy of fine-needle aspiration cytology of thyroid gland lesions: A study of 200 cases in Himalayan belt. J Can Res Ther 2017;13:4515

9. Sengupta M, Das I, Basu K, Das C, Ara, Islam N. A Cytohistological Correlation in Thyroid Swelling with Special Reference to The Bethesda System: A Study of 192 Cases. IOSR Journal of Dental and Medical Sciences (IOSR-JDMS) 2017; 16 (10): 55-9.

10. Chandanwale SS, Nair I, Gambhir A, Kaur S, PandeyA,Shetty A. Cytomorphological Spectrum of Thyroiditis: A Review of 110 Cases. Hindawi Journal of tyroid Research 2018; Volume 2018;Article ID 5246516: 1-7 